\title{
The Relationship Between Social Media Addiction, Self- Esteem, Sensation Seeking and Boredom among College students
}

\author{
Tanvi Pawar ${ }^{1}$, Jeel Shah ${ }^{2}$ \\ ${ }^{1,2}$ Department of Psychology, Maniben Nanavati Women's College, Mumbai \\ Corresponding Author: Tanvi Pawar \\ Email-tanvipwr57@gmail.com
}

\begin{abstract}
Background: In today's era millennials are caught in the trap of social media addiction which has pervasive effects. The present study would examine the social media addiction among 105 college students, between the age range of 18 to 30 years. Previous studies have highlighted that psychological attributes like Anxiety, Depression, Shyness, Loneliness, and Boredom are strongly associated with people who use social media excessively.

Methodology: For the purpose of data collection, the tools used are: Social Media Addiction Scale, Rosenberg Self-Esteem Scale, Brief Sensation-seeking Scale and Boredom scale. To verify the hypotheses of the study statistical analysis used were Descriptive Statistics, Correlation and for further analyses regression was carried to see the social media addiction as predictor for the other dependent variables.

Results: Results found the significant relationship between social media addiction andn boredom and selfesteem. No significant relationship was found between social media addiction and sensation-seeking.

Conclusion: As per the results obtained from the Correlation Hypothesis 1 that is there will be a significant relationship between Social Media Addiction and Self-esteem and Hypothesis 3 that Social media addiction and Boredom were proved and Hypothesis 2 that is, there will be a significant relationship between Social Media Addiction and Sensation Seeking was not proved.
\end{abstract}

Keywords: Social media addiction, self-esteem, sensation-seeking, boredom, college students.

(Paper received $-10^{\text {th }}$ December 2019, Peer review completed $-29^{\text {th }}$ December 2019)

(Accepted $-29^{\text {th }}$ December 2019)

\section{INTRODUCTION}

The world that we live in today is a world full of technological marvels. Everywhere we look and every aspect of our lives has been influenced and moulded by the plethora of gadgets and applications that have come up at an astounding pace to overwhelm and overhaul the economic, political, social and psychological fabric of our everyday lives. For many of us it would be unfathomable to function without the conveniences that technology has brought about into our everyday lives. It is observed that there is a predominant use of smartphones.

Psychiatrist and Psychologists say the Smartphone addiction has rose up to $75 \%$ among people between 1835 years in only year. The global survey by B2X Care Solutions (2014) a provider of customer care for smartphones, $98 \%$ Indians sleep with their smartphones and $83 \%$ keep it on their body or within reach throughout the day [1].

One of the main causes of using smartphones in excess is to access social networking sites in today's era. Social network sites as web-based services that allow individuals to (1) construct a public or semi-public profile within a bounded system, (2) articulate a list of other users with whom they share a connection, and 
(3) view and traverse their list of connections and those made by others within the system. The nature and nomenclature of these connections may vary from site to site [2]. The more sought-after social media platforms today consist of: Whatsapp, Instagram, Snapchat, Facebook, Twitter, dating applications like Tinder. Global Windex's latest social media usage report shows that more than $40 \%$ of people use social media platforms to keep in touch with friends, making this the top reason for social media use globally. Among 16 to 24 years-old, the key reason for using social media is not to keep in touch, but rather to fill spare time, while among 25 to 34 years old, staying in touch with friends proves more important. In the 34 to 44 years-old bracket it comes down to staying up-to-date with news and current affairs [3]. The current study examined the relationship between Social media addiction, self-esteem, sensation seeking and boredom in 100 college students between the age of 18 to 30 years. Addiction usually refers to compulsive behaviour that leads to negative effects. In most addictions, people feel compelled to do certain activities so often that they become a harmful habit, which then interferes with other important activities such as work or school.

In that context, a social networking addict could be considered someone with a compulsion to use social media to excess -- constantly checking Facebook status updates or "stalking" people's profiles on Facebook, for example, for hours on end [4].

Self-esteem is a widely used concept both in popular language and in psychology. It refers to an individual's sense of his or her value or worth, or the extent to which a person values, approves of, appreciates, prizes, or likes him or herself [5]. "Sensation seeking is a personality trait defined by the search for experiences and feelings, that are varied, novel, complex and intense, and by the readiness to take physical, social, legal, and financial risks for the sake of such experiences [6]. Boredom has been defined in terms of its main central psychological processes: "an unpleasant, transient affective state in which the individual feels a pervasive lack of interest and difficulty concentrating on the current activity" [7]. In the first section of the study the hours of social media usage were also enquired in the study to obtain a quantitative measure of the social media usage and the reason for using social media was also noted.

Social Media Addiction is a burning issue amongst youths in today's era. According to the 2018 statistics, 45 percent of teenagers are almost constantly online and use apps like snapchat and Instagram in dominance. Several variables are thought to be correlated with social media addiction like depression, anxiety, shyness [8-9]. The variables under study in the present paper is the relationship between social media addiction, selfesteem, sensation seeking and boredom. It is hypothesized that there will be a significant relationship between social media addiction and self-esteem, social media addiction and sensation seeking and social media addiction and boredom.

In a research paper, [10] the variables addressed were the relations among social media addiction, self-esteem and life satisfaction amongst university students. The result showed addictive use of social media had a negative association with self-esteem, and the latter had a positive association with satisfaction with life. Furthermore, path analysis showed that self-esteem mediated the effect of social media addiction on satisfaction with life. In another research paper by [11] the variables addressed were social media and selfesteem and it was hypothesized that the upward comparisons made using social networking sites have caused people to have lower self-esteems. The results suggest that approximately $88 \%$ people engage in making social comparisons on Facebook and out of the $88 \%, 98 \%$ of the comparisons are upward social comparisons. Further this research proves there that there is a strong relationship between social media and self-esteem. Increase in social media usage causes the self-esteem of individuals to decrease. A study worked with the likes of internet addiction and personality in association with traits such as impulsive sensation seeking and neuroticism [12]. This study was carried out on students of the age 18-24 years and the results suggested the prevalence of internet addiction was $31.8 \%$, with moderate and severe use of internet at $30.7 \%$ and $1.1 \%$, respectively. Based on multiple logistic regression analysis, the impulsive sensation seeking and neuroticism-anxiety traits were found to be significantly associated with internet addiction. Another paper which focused on variables like leisure, boredom, sensation seeking, self-esteem, addiction symptoms and patterns of mobile phone usage showed that the higher one scored on sensation seeking and leisure boredom, the higher the likelihood one was addicted to the mobile phone. Conversely, subjects who scored high on self-esteem -- who perceived themselves as being in control demonstrated less of a tendency to be addicted 
[13]. Regression results also indicate that sensation seeking played the largest role in mobile phone addiction, while gender, self-esteem, and leisure boredom appeared to have a lesser but significant influence.

\section{METHODOLOGY}

\section{Research Questions}

- Has social media addiction contributed to low Self-esteem amongst college students?

- Has social media addiction contributed to higher Sensation Seeking amongst college students?

- Is social media addiction on a rise due to Boredom amongst college students?

Aim

To determine the relationship between social media addiction, self-esteem, sensation seeking and boredom among college students.

\section{Hypothesis}

1. There will be a significant relationship between Social Media Addiction and Self-esteem.

2. There will be a significant relationship between Social Media Addiction and Sensation Seeking.

3. There will be a significant relationship between Social Media Addiction and Boredom.

\section{Variables}

The variables under study were -

1. Social Media Addiction

2. Self-esteem

3. Sensation Seeking

4. Boredom

\section{Research Design}

A quantitative correlation study was employed using survey method. A correlational study was used to find if there exists a relationship between two variables. It studied whether an increase or decrease in one variable corresponds to an increase or decrease in the other variable. For further analyses regression was carried to see the social media addiction as predictor for the other dependent variables.

\section{Sample and Sampling Design}

Data was gathered from a Randomised sample of 105 college students ranging in age from 18 to 30 $(M=20.06, S D=2.43)$ who responded to a survey which was generated using Google forms in November 2018. The age range of 18 to 30 years old were targeted as they were the heaviest users of social media in India [14]. The Google forms were circulated and interested candidates were requested to be part of the study and were also requested to send the form to their contacts as well. Non eligible respondents (below the age of 18 and above the age of 31), the ones who weren't on any social networking site were excluded. The sample consisted $35.6 \%$ of Male respondents and $64.4 \%$ of Female respondents (Male $=37$, Female $=68$ ).

\section{Instruments used}

Social Media Addiction Scale [15]: A 5-point Likert type scale which consists of 29 items with the Internal consistency coefficient (Cronbach's alpha coefficient) was found .93 for the whole scale and at values ranging from .81 to .86 for the sub-factors. Test-retest coefficient was found .94. In conclusion, SMA-SF is a 5-point Likert-type scale consisting of 29 items grouped under 4 factors (virtual tolerance, virtual communication, virtual problem and virtual information). The psychometric properties of scale indicate that the scale is valid and reliable enough to be used in determining the social media addictions of secondary school, high school and university students. The score range is $29-145$. The higher scores indicate that agent perceives himself as a "social media addict". 
Self-esteem: The 10 item Rosenberg Self-esteem scale was used to assess self-esteem. Reliability and validity have been established across age groups and in different countries. A sample of 391 adults ages 19 to 90 , found Cronbach's alpha for 27 the total scale was 0.83 [16].

Sensation Seeking: A 5-point scale was used with $1=$ would never try and $5=$ often do. The adventureseeking sub-scale, consisting 4 items from the 4-dimension sensation-seeking scale, was adapted from Zuckerman and others to assess desire to engage in sports-related and other activities involving speed or danger (Cronbach's alpha $=0.78)$ [17].

Boredom: -Boredom Proneness Scale (BPS- Short Form), a commonly used measure of trait boredom, developed by Struk, Carriere, Cheyne and Danckert. The scale comprises of 5-point Likert scale having 8 items. The scale demonstrated uni-dimensionality and the scale score had good internal consistency and construct validity comparable to the original BPS score [18].

\section{STATISTICAL ANALYSIS}

To verify the hypotheses of the study statistical analysis used Descriptive Statistics, Correlation and for further analyses regression was carried to see the social media addiction as predictor for the other dependent variables.

\section{RESULTS}

The main aim of the study was conducted to find the relation between Social Media addiction, Self-esteem, Sensation seeking and Boredom among college students in Mumbai. The sample size was 105 with both males and females. The mean hours of social media usage were $4.66(\mathrm{SD}=3.62)$. The mean Social media addiction score found was $74.80(\mathrm{SD}=15.75)$. The mean Boredom score was $21.266(\mathrm{SD}=6.50)$. The mean sensation seeking score scale was $21.266(\mathrm{SD}=5.20)$. The mean Self- esteem score was $28.90(\mathrm{SD}=5.11)$. A detailed descriptive review of the four variables has been given in Table 1.

Table 1: Descriptive Statistics

\begin{tabular}{|l|l|l|l|}
\hline & $\mathrm{N}$ & Mean & Std. Dev. \\
\hline Social Media Addiction & 105 & 74.80 & 15.75 \\
\hline Boredom & 105 & 21.26 & 6.50 \\
\hline Sensation-Seeking & 105 & 28.02 & 5.20 \\
\hline Self-Esteem & 105 & 28.90 & 5.11 \\
\hline
\end{tabular}

Initially, a Correlation Analysis was conducted to find the relationship shared by Social Media Addiction, Boredom, Sensation Seeking and Self-Esteem (reported in Table 2).

Table 2: Correlational analysis among the variables Social Media Addiction, Boredom, SensationSeeking \& Self-Esteem $(n=105)$

\begin{tabular}{|l|l|l|l|}
\hline & Boredom & Sensation-Seeking & Self-Esteem \\
\hline Social Media Addiction & $0.5048^{* *}$ & 0.093 & $-0.291^{* *}$ \\
\hline
\end{tabular}

** significant $(\mathrm{p}<0.01)$

Results obtained showed significant positive association with Social Media Addiction and Boredom ( $\mathrm{r}=$ 0.504; $\mathrm{p}<0.01)$ and a significant negative association with Self-esteem $(\mathrm{r}=-0.291 ; \mathrm{p}<0.01)$. However no association was found between Social Media Addiction ( $r=0.093$; NS). 
A series of Regression Analyses were then conducted to estimate the extent to which social media addiction could predict the other variables (reported in Table 3).

Table 3 (a): Regression analysis predicting Boredom from Social Media Addiction

\begin{tabular}{|c|c|c|c|c|}
\hline $\mathrm{R}$ & $\mathrm{R}^{2}$ & $\mathrm{~F}$ & $\mathrm{df}$ & $\mathrm{p}$ \\
\hline 0.504 & 0.254 & 35.08 & 1,103 & 0.01 \\
\hline
\end{tabular}

Table 3 (b): Regression analysis predicting Sensation-Seeking from Social Media Addiction

\begin{tabular}{|c|c|c|c|c|}
\hline$R$ & $\mathrm{R}^{2}$ & $\mathrm{~F}$ & $\mathrm{df}$ & $\mathrm{P}$ \\
\hline 0.093 & 0.009 & 0.896 & 1,103 & $\mathrm{NS}$ \\
\hline
\end{tabular}

Table 3 (c): Regression Analysis predicting Self-Esteem from Social Media Addiction

\begin{tabular}{|c|c|c|c|c|}
\hline $\mathrm{R}$ & $\mathrm{R}^{2}$ & $\mathrm{~F}$ & $\mathrm{Df}$ & $\mathrm{p}$ \\
\hline 0.291 & 0.085 & 9.528 & 1,103 & 0.01 \\
\hline
\end{tabular}

The results show that Social Media Addiction could predict boredom significantly $\left(\mathrm{R}=0.504, \mathrm{R}^{2}=0254, \mathrm{~F}\right.$ $(1,103)=p<0.001)$.On the other hand, Social Media Addiction was able to predict Self-esteem with significant accuracy $\left(\mathrm{R}=0.291, \mathrm{R}^{2}=0.085, \mathrm{~F}(1,103)=9.52 ; \mathrm{p}<0.001\right)$. Social Media Addiction was also not able to predict Sensation Seeking significantly $\left(R=0.093, R^{2}=0.009, F(1,103)=0.89\right.$; NS).

\section{DISCUSSION}

The first section of the questionnaire enquired for how many hours social media is used by each respondent on a daily basis. This was asked to get a quantitative measure of the social media access and to obtain a floor and ceiling amongst the study group. In the study population it was found that the average of social media usage ranged between 3 to 10 hours. The Results suggested a negative correlation between social media addiction and self-esteem i.e., there is increase in social media addiction with decrease in self-esteem, the people higher hours of social media usage showed lower self-esteem. These results are similar to those of studies which showed that spending more time on social media or being addicted to social media can result in more social comparison orientation thus resulting in lower levels of self-esteem [10]. The results were also in line with the findings which suggested that self-esteem decreases as a result of the upward or downward comparisons with people in the social world [11]. No significant correlation was found between social media addiction and sensation seeking mainly because the scale used i.e., The adventure-seeking sub-scale, consisting 4 items from the 4-dimension sensation-seeking scale, was adapted from Zuckerman to assess desire to engage in sports-related and other activities involving speed or danger was mainly related to adventure related sensation seeking and had very less context to our daily life [16]. Out of the three variables the most significant found was boredom in relationship with social media addiction. These findings were in line with the study on Malaysian students, where results suggested that higher a person scored on the boredom scale higher the person was like to be an internet addict [13]. In the first section of the study the study population was asked the reason of social media usage and the two main reasons highlighted were Boredom and time pass which is also in line with the findings of the study with boredom being the strongest predictor of social media addiction amongst the three variables. The variety of social media application available today with easy accessibility allows one to engage in it when bored. As the current study show 
social media usage due to low self -esteem which allows us to infer people who that they would prefer virtual engagement more compared to real stimulations

\section{CONCLUSION}

As per the results obtained from the Correlation Hypothesis 1 that is there will be a significant relationship between Social Media Addiction and Self-esteem and Hypothesis 3 that Social media addiction and Boredom were proved and Hypothesis 2 that is, there will be a significant relationship between Social Media Addiction and Sensation Seeking was not proved. With the results obtained from the Regression Analysis it can be rightly said that Social Media Addiction exists in youth but Self-esteem and Boredom are strong predictors of it.

\section{Limitations of the study and scope for further research}

While the trends observed are certainly robust, and thus can form the basis for intervention development; this study nevertheless suffers from certain shortcomings. The sample size was small allowing less generalizability. The chosen sample was from the city of Mumbai, and thus, may be representative of only urban, metropolitan locations. For the purpose of this study, gender, personality, and socio-economic status were not controlled, and it would be interesting to conduct further research on the impact of these variables on the trends observed. It would also be interesting to conduct cross cultural studies of the phenomenon of usage of social media. It would also be good to explore rural - urban differences in the impact of social media addiction and also the identify the specific social media addiction.

\section{REFERENCES}

1. Rajan N. Smartphone addiction: $98 \%$ Indians sleep with their devices says global survey. Financial Express. 2014 Dec 11. Available from: https://www.financialexpress.com/industry/technology/smartphoneaddiction-98-indians-sleep-with-their-devices-says-global-survey/17912/

2. Boyd DE. Social network sites: Definition, history, and scholarship. J Comp Mediated Commun 2008;13(1):210-30.

3. Ahmad I. Top 10 reasons for using social media. Social Media Today. 2017 Jul 27. Available from: https://www.socialmediatoday.com/social-networks/top-10-reasons-using-social-media-study

4. Walker L. What is social networking addiction? Lifewire. 2019 Dec 29. Available from: https://www.lifewire.com/what-is-social-networking-addiction-2655246

5. Gottheim CP. Self-esteem, self-compassion, defensive self-esteem, and related features of narcissism as predictors of aggression. State University of New York at Albany; 2009.

6. Zuckerman M, Kolin EA, Price L, Zoob I. Development of a sensation-seeking scale. J Consult Clin Psychol 1964;28(6):477-80.

7. Fisherl CD. Boredom at work: A neglected concept. Hum Relat 1993;46(3):395-417.

8. Kircaburun K. Self-Esteem, Daily Internet Use and Social Media Addiction as Predictors of Depression among Turkish Adolescents. J Educ Pract 2016;7(24):64-72.

9. Seabrook EM, Kern ML, Rickard NS. Social networking sites, depression, and anxiety: a systematic review. JMIR Mental Health 2016;3(4):e50.

10. Hawi NS, Samaha M. The relations among social media addiction, self-esteem, and life satisfaction in university students. Soc Sci Comp Rev 2017;35(5):576-86.

11. Jan M, Soomro S, Ahmad N. Impact of social media on self-esteem. Eur Scientific J 2017;13(23):329-41.

12. Othman Z, Lee CW, Kueh YC. Internet addiction and personality: association with impulsive sensation seeking and neuroticism-anxiety traits. Int Med J 2017;24(5):375-8.

13. Leung L. Leisure boredom, sensation seeking, self-esteem, and addiction. Med Interpers Commun 2008;1:35981.

14. Bhardwaj A, Avasthi V, Groundar S. Impact of Social Networking on Indian Youth-A Survey. Int J Electr Inform Engineer 2017;7(1):41-51.

15. Sahin C. Social Media Addiction Scale-Student Form: The Reliability and Validity Study. Turkish Online Journal of Educational Technology-TOJET 2018;17(1):169-82. 
16. Robins RW, Hendin HM, Trzesniewski KH. Measuring global self-esteem: Construct validation of a singleitem measure and the Rosenberg Self-Esteem Scale. Personal Soc Psychol Bull 2001;27(2):151-61.

17. Zuckerman M. The psychophysiology of sensation seeking. J Personality 1990;58(1):313-45.

18. Farmer R, Sundberg ND. Boredom proneness--the development and correlates of a new scale. J Personal Assess 1986;50(1):4-17.

\section{Acknowledgements - Nil \\ Conflict of Interest - Nil \\ Funding - Nil}

